\title{
Barriers to Construction Health and Safety Self-regulation: A Scoping Case of Nigeria
}

\author{
Umeokafor, N. ${ }^{1}$
}

\begin{abstract}
This scoping study builds on the recent uncovering that in terms of health and safety (H\&S), the Nigerian construction industry is self-regulated in various forms, not unregulated and that the size of company can further explain H\&S self-regulation. Consequently, the barriers identified through literature review were assessed using questionnaires. Analysis of the data collected from construction practitioners in Nigeria shows that 'economic factors' mostly explains the barriers to construction H\&S self-regulation. This is followed by the 'ability to self-regulate' and 'lack of awareness'. Furthermore, the results show significant differences among small, medium and large construction contractors on seven factors of which include 'normative case' factors, 'H\&S is a duty', 'H\&S is the right thing' and 'unfair H\&S standards or legislation'. Although a scoping study, the study draws attention to the barriers to construction H\&S selfregulation in Nigeria and demonstrates an alternative to state regulation of H\&S.
\end{abstract}

Keywords: Barriers; health and safety; Nigeria; private regulation; regulation.

\section{Introduction}

While the Nigerian construction industry continues to contribute to the economy of the country, there is evidence in studies that it is performing poorly in terms of health and safety (H\&S) [1-4]. According to authors, the unregulated nature of the Nigerian construction industry in terms of H\&S remains among the factors responsible for the poor state of construction H\&S in Nigeria $[1,2,5,6]$. This is where there is no local H\&S legislation covering the Nigerian construction industry [1,5], thus contractors adopt and implement H\&S laws and standards from developed countries [1], the local National Building Code [7] which has no legislative backing [8], and the H\&S standards set by the oil and gas sector.

Conversely, while Umeokafor and Isaac [9] admit that there is no local H\&S law covering the Nigerian construction industry, they conclude that some parts of the industry are self-regulated in various forms because of the aforesaid actions of the contractors in the preceding paragraph.

\footnotetext{
1 Department of Built Environment, Faculty of Architecture, Computing \& Humanities, University of Greenwich, London, UK. E-mail: nnedinmaik@hotmail.com
}

Note: Discussion is expected before June, $1^{\text {st }} 2017$, and will be published in the "Civil Engineering Dimension", volume 19, number 2, September 2017.

Received 07 February 2017; revised 10 March 2017; accepted 24 March 2017.
This stems from the concept of self-regulation in studies such as Aalders and Wilthagen [10], Christmann and Taylor [11], Havinga [12], Hutter [13] where organisations or the industry develop, adopt and administer standards, programmes, and policies with little or no external involvement.

The uncovering that the Nigerian construction industry is self-regulated in various forms and not unregulated as has been long perceived indicates that H\&S issues in the industry have been addressed from only a state regulatory perspective, overlooking self-regulation. The concept of H\&S selfregulation presents a lens to view improving construction H\&S, especially in developing countries such as Nigeria where there is little or no state involvement in H\&S. This is especially vital as there is evidence of self-regulation improving H\&S in various studies; for example, see Finger and GamperRabindran [14] and Scharrer [15]. However, what remain poorly understood are the barriers to $\mathrm{H} \& \mathrm{~S}$ self-regulation in Nigeria's construction industry and the extent that these factors hinder H\&S selfregulation.

In addressing the aforesaid gap in knowledge, it is vital to consider the size of contractors for many reasons. Firstly, there is evidence that the size of contractors determines their performance in terms of H\&S [4,16-18]. Secondly, the characteristics and challenges of these contractors vary according to their sizes. For instance, large construction firms are well placed to engage in H\&S $[4,17]$ in terms of finance, awareness level and management commitment to H\&S. This is against small or medium-sized 
firms who are hindered by, inter alia, lack of funds $[17,19]$, low level of awareness on H\&S [16,18], low level of management commitment to H\&S [17] hence performing poorly H\&S-wise [16,17]. Mills and Lin [17] show that the poor performance of small construction contractors is pronounced when compared with large contractors. This may explain the findings of Walls and Dryson [20] where small manufacturing firms are less likely to provide employees with information on confined spaces and material safety data sheets. As a result, authors emphasise that regulatory strategies should factor in the size of firms [21]. Correspondingly, Idoro [2] notes the imperativeness of creating awareness among stakeholders in the construction industry on the contributions of contractors based on their categories.

Consequently, the overarching aim of this study is to identify and assess barriers to H\&S self-regulation in the Nigerian construction industry, factoring in the sizes of the companies. This area remains underexamined if not unexamined in literature, especially in developing countries such as Nigeria.

\section{Literature Review}

\section{Overview of Construction Health and Safety in Nigeria}

Like most construction industries in developing countries, the Nigerian construction industry is hazardous and characterized with poor construction and H\&S practices [3,22], which result in poor H\&S records [4]. Typically, the use of faulty tools and equipment that may be explained by the lack of knowledge and skills for maintenance, which are mostly foreign, increases hazardous conditions on the construction sites [22]. Also, there is a high level of non-compliance with H\&S standards [6,22], nonwearing of personal protective equipment [3] to name but two. This may explain the poor H\&S records in projects that authors such as Windapo and Jegede [4] report. Windapo and Jegede [4] found that 22 of their respondents from indigenous small and medium-scale (SME) contractors have witnessed fatalities while one of the respondents from a multinational contractor, which are mostly large contractors, has witnessed fatality.

\section{Relating Size of Construction Contractors to Health and Safety}

The sizes of contractors as can be seen in studies [4,16-19,23] may to some extent explain the poor H\&S record of the construction industry. In particular, while large contractors may be impacted significantly by the H\&S regulatory framework because of factors such as preservation of image,
Kheni et al. [16] note the contrast for small and medium (SME) contractors in that the regulatory framework for H\&S barely influences the ownersmanagers. This may be explained by the position of Anderson and Russell [19] who demonstrate a higher financial and resources implications of regulation on small firms than on large firms. According to the findings of Wong et al. [24], lack of resources and funds highly contribute to unsafe construction practices. These, among many, in turn, determine the attitudes and commitment of small and even medium-sized businesses towards H\&S, which is reported as poor in some studies $[16,18]$. This is where these small businesses perceive complying with laws as burdensome [19] and engaging on H\&S as unimportant [24] and a cost [23].

The scope of operation of construction contractors may to some extent also explain the difference in performance that the sizes of contractors present. This is because large projects are likely to present more risk, funds and attention to H\&S than small projects where the risk, funds and attention to H\&S may be less. The above premises tend to be adduced by the position of authors such as Mills and Lin [17]. Typically, Mills and Lin [17] suggest that the scope of the project of small and large contractors may explain the poor performance of small contractors in that they handle mostly small value projects thus their H\&S plans may not be comprehensive. This is against large contractors that have large value projects thus robust H\&S plans [17]. In a bid to survive, the findings of Kheni et al. [16] evidence that construction SMEs prioritise profit-making over H\&S. This may prompt the rare use of safety equipment and maintenance of tools in small contractors, which is in contrast to what obtains in large contractors, as Agumba and Haupt [23] suggest or employing incompetent persons.

From a management perspective, a study by Mills and Lin [17] evidences that among small contractors, the management commitment to H\&S management (such as H\&S review, involvement in the design process) is very low compared to the management commitment in large contractors. This is in addition to small contractors who were found not to have safety committees [17]. The foregoing points in this section explain a study that demonstrates that in benchmarking small firms with large firms, the former lack the ability and motivation to achieve optimum H\&S [17].

However, there are indications that family values drive good H\&S practices in some of these small businesses [18]. This is, in addition, the high level of management commitment to H\&S among SMEs contractors [23]. There is evidence of the top management of SMEs supporting H\&S, and management 
approved H\&S improvement goals, which prompt H\&S culture that promotes employees participation in H\&S matters [23]. Although the small sample of the study by the aforesaid authors limits its generalization [23], it offers optimism to the attitudes of SMEs towards H\&S. Nonetheless, in tackling H\&S challenges, the differences presented by the varying sizes of the firm are crucial.

\section{Regulation of Health and Safety in Nigeria}

While the size of firms remains critical in H\&S, regulating these firms also remains significant in achieving H\&S. However, in Nigeria, the regulation of construction H\&S remains elusive because of many factors such as the dysfunctional and fragmented H\&S regulatory system, the inadequate H\&S laws. The existing H\&S law covering many workplaces in Nigeria is the Factories Act [25], empowers the Inspectorate Division of the Federal Ministry of Labor and Productivity to enforce the law. The Factories Act originates from the UK [1,2] with little or no consideration of the environment of Nigeria [22]. Consequently, they are impracticable in Nigeria [22] failing to address the issues relating to Nigeria. Worse still, the Factories Act is characterized with significant anomalies; thus, authors conclude that it is grossly inadequate $[1,2,5,6]$. Such anomalies are not limited to the fact that the Factories Act does not cover construction sites and activities, thus the industry is reported as unregulated $[1,2,5]$. As a result, some construction contractors adopt and enforce H\&S standards, policies and programmes from developed countries [1]. Further, the background established so far has prompted the legislative arm of a state in Nigeria, Lagos, to establish a legislation-backed safety commission. According to Lagos State Safety Commission Law [26], the commission is to, among many, set safety standards, enforce, and monitor all sectors in the state. This, of course, includes the construction industry of the state.

Drawing on the background established so far and the concept of self-regulation [10], Christmann and Taylor [11], Havinga [12], Hutter [13], Umeokafor and Isaac [9] conclude that H\&S regulation in the Nigerian construction industry is self-regulated in various forms and not unregulated. The adoption and administration of H\&S standards, policies and programmes from developed countries [1-2] is a form of self-regulation [9]. The same can be said of the adoption and implementation of the National Building Code [7] by many contractors despite that it is yet to receive legislative backing [8]. National Building Code addresses, among many, H\&S challenges from pre-design stage to post-construction stage. Other ways that the Nigerian construction industry is self-regulated is when clients and bodies both international and local get contractors to engage in H\&S [9] and the contribution of the Lagos State Safety Commission that is noted in the preceding paragraph. Umeokafor and Isaac [9] offer a treatise on H\&S self-regulation in Nigeria, demonstrating other ways that the Nigerian construction industry is self-regulated covering, pure self-regulation, industry regulation, enforced self-regulation, and client-led self-regulation.

\section{Overview of Self-regulation}

The failure of deterrence based strategies to perform up to expectation prompted alternative regulatory approaches such as self-regulation [10,27]. Self-regulation depends on country, organization, and industry [27]. The flexibility of self-regulation increases its ability to address changing circumstances, fitting into the ability of firms [19]. Self-regulation is of the premise that risk creators are better in controlling the risks [28]. Anderson and Russell [19] view that self-regulation can address the regulatory issues that are mostly found in small firms.

Self-regulation has been evidenced to improve H\&S in many studies [14-15]. In particular, Finger and Gamper-Rabindran [14] found that chemical manufacturing firms that take part in Responsible Care (RC) a H\&S self-regulatory programme, were likely to enjoy a $69.3 \%$ reduction in accidents, an $85.9 \%$ reduction in process safety accidents, and accidents due to non-complaince with RC codes. Additionally, as construction contractors in Nigeria self-regulate [9], evidence in studies such as Windapo and Jegede [4] where multinationals have a better H\&S record than the indigenous contractors can be argued to be due to self-regulation.

However, there are concerns about self-regulation. The interest of one of the parties such as the public and industry involved in self-regulation may not be protected if there is state involvement [27]. This is in addition to the possibility of low standards in selfregulatory activities, especially in cases such as Nigeria where the regulatory system is fragmented. There is evidence that H\&S self-regulation has failed in New Zealand [20]. Walls and Dryson [20] found that $44 \%$ of their respondents complied with basic H\&S steps such as hazard identification. Only 11\% of the respondents adopted engineering controls such as effective ventilation, rather a lot adhere to personal protective equipment control, which is last on the risk control hierarchy.

\section{Identifying the Barriers of Health and Safety Self-regulation}

Determinants of H\&S self-regulation can be identified and analyzed with the framework in Umeo- 
kafor and Isaac [9]. The framework is made up of the elements below which are influenced by the social, political, economic and cultural environments of Nigeria.

- Regulatory case. From the work of King and Lenox [29], regulatory activities, which are barriers to H\&S self-regulation can be identified. When the activities of the regulator are perceived as unfair [28], the regulated will not be motivated to self-regulate. Umeokafor and Isaac [9] argue that the level of external involvement determines if the regulated will regulate. This is because if the regulated is involved, they will have a sense of belonging and their interests represented [9]. Other factors in Table I that can be classified under the regulatory case are factors such as inadequate H\&S legislation [5], assurance that there will not be persecution if the regulated does not self-regulate in terms of H\&S, complex H\&S legislation. Giuliano and Linder [30] cover the regulatory case for self-regulation in detail.

- Ability to self-regulate. While factors such as the complex H\&S legislation fall into the regulatory case, they also determine the ability of the regulated to self-regulate. According to Umeokafor and Isaac [9], this is where the regulated wants to self-regulate, but they are unable to self-regulate because of factors such as the high cost of H\&S practices, lack of awareness, and complex H\&S legislation.

- Economic case. While the high cost of H\&S practices or lack of funds determines the ability of the regulated to self-regulate, it also makes an economic case for self-regulating or not. The regulated will consider the cost of self-regulating, the implications of not-self-regulating such as loss of contract, prosecution, direct and indirect cost of accidents, and decide to self-regulate or not [9]. So the regulated prioritises, profits or economic gains over H\&S [16,18].

- Social pressure. The impact of pressure from the society will make firms self-regulate as can be seen in studies $[29,30]$. This means that if the organization does not care about its reputation, it will not self-regulate (cf. [29]). Also, if there is pressure from pressure groups not to selfregulate the regulated may be demotivated from self-regulating as per H\&S.

- Organizational case. According to Umeokafor and Isaac [9] these are factors within the organization that support or do not support H\&S self-regulation. The following factors in Table 1 fall under the organizational case: lack of positive H\&S culture in the organization, stakeholders in organizations not supporting H\&S self-regulation, and organizational norms and values do not support H\&S. The scope of operation of the firm also determines self-regulation $[11,17]$. Also, lack of management commitment to $H \& S$ can also be a barrier to H\&S self-regulation [9,17].

- Normative case: This is related to the moral stand of the regulated and/or the level of legitimacy attached to H\&S legislation [9,30]; (cf. [31]). Therefore, if the legislation is viewed as unfair, or the regulated does view it as a duty to self-regulate, or the regulated view H\&S selfregulation as wrong, they will not self-regulate (Table 1).

- Industry case. Here, Christmann and Taylor [11], King and Lenox [29] and Umeokafor and Isaac [9] demonstrate, suggest or adduce that factors relating to the nature or structure of the construction industry fall into this case. For example, the negative attitude from members of construction supply chain (such as client, subcontractor) can be a barrier [9]. Additionally, just as the scope of project, the requirements in the industry, peer-pressure from fellow companies can drive H\&S self-regulation [9,17], they can also be barriers to H\&S self-regulation.

- Power relationship case. The regulated or the industry weighs their power of influenceability or resistance in the society and decides to selfregulate or not [9]. Thus, low level of influenceability in Table 1 fits into this case.

\section{Methodology}

The study reported in this paper sought to identify and assess the barriers of H\&S self-regulation in the Nigerian construction industry. Using the framework for analyzing the determinants of construction H\&S self-regulation [9], 28 barriers were identified through the literature survey and interviews with H\&S experts in the Nigerian construction industry. The factors were then used to design the questionnaires, pre-tested on academics and practitioners in the industry alongside interviewing of two practitioners. The questionnaires were then revised before distribution. The academics completed the study based on a project they recently completed, as they had part-time practitioner roles in the industry alongside their academic roles.

The first part of the questionnaires identified the demographic information of the respondents. This demonstrated among many the experiences of the respondents, improving the credibility and reliability of the information provided by the respondents on the subject. The second part then identified and assessed the barriers of H\&S self-regulation in the Nigerian construction industry. The questions were in the Likert scale of $1-5$, where ' 1 ' is very low and ' 5 ' very high in terms of the impact of the factors on H\&S self-regulation. 
Using the aforesaid analytical tool by Umeokafor and Isaac [9] stems from the following. Firstly, the tool has been designed for the construction industry with emphasis on the Nigerian construction industry. This means that a lot of the issues addressed in designing the tool may fit into the concept of selfregulation in Nigeria. Secondly, according to the authors, experts and academics validated the tool [9]. Thirdly, the tool was the only analytical tool for construction H\&S self-regulation that was found.

Due to financial constraint, time factor, and that there is no comprehensive list of contractors in Nigeria, non-probability sampling was adopted. Research assistants distributed 62 questionnaires in Nigeria covering the following states: Abuja, Anambra, Ebonyi, Enugu, Kogi, Lokoja, and Rivers. The research assistants explained the concept of H\&S self-regulation to the respondents. The respondents include architects, builders, engineers, project managers, safety officers. Some lecturers completed the questionnaires, but theirs were not used, as it was unclear if they had practitioner experience as at the time of completing them. The respondents were from large, medium, and small contractors. Large contractors are conceptualized in this study to be contractors that employ over 250 staff [16] while small contractors employ less than 50 staff [18] and medium contractors employ above 50 but less than 250 staff.

In total 44 usable questionnaires were returned and statistics package for social science (SPSS) was used to analyze the data where mean statistics, one-way ANOVA, and multiple comparison tests (Tukey HSD) were conducted. The one-way ANOVA compared the independent means of the responses of the three categories of the construction contractors (large, medium, and small) to see if there is a difference among them; then the Tukey HSD test showed the exact groups with the differences. However, Tukey HSD tests can find the difference between two group means where the one-way ANOVA does find any difference [32-33] just as ANOVA can be significant but the Tukey HSD is not [32].

Importantly, it can be argued that strong conclusions cannot be drawn from the findings of the current study, but the author views that the findings of the study may not be significantly different from a larger sample. The current study should be viewed as a scoping study. Nonetheless, there are a few other points that make a case for publishing the current paper. Firstly, the study will contribute to H\&S research in developing countries which receives little attention according to authors such as Puplampu and Quartey, [34] Tanko and Anigbogu [35], hence the dearth of H\&S literature in developing countries (also see [2,5]). Secondly, that a sample is small does not mean that statistical studies should not be conducted as small-sample studies are like using binoculars to make an astronomical observation [36,37]. Studies such as Umeokafor [37] have published scoping studies in high-ranking journals with small samples such as the current study. Similarly, Ramos et al. [38] present a pilot study with a small sample of 40 respondents but acknowledge the limitation of the small sample.

\section{Results}

\section{Background Information of the Respondents}

Of the 44 respondents, $12(27.3 \%)$ are from the small-sized contractors, 19 (43.2\%) from mediumsized contractors, and 13 (29.5\%) from large-sized contractors. The years of work experience of the 8 (18.2\%) respondents range from $0-5$ years, 9 (20.5\%) had between 6-10 years of work experience. The respondents with between 11 and 21 years of work experience were seven in total (15.9\%), and 20 $(45.5 \%)$ had over 25 years of work experience in the construction industry. Their current designations in their organizations are as follows: seven builders, 13 project managers, three architects, 11 civil engineers, three safety officers. Others were six quantity surveyors and one water and soil engineer/project manager.

\section{Barriers to Health and Safety Self-regulation}

Table 1 shows that of all the factors surveyed, no factor ranks the same for the three categories of contractors. This supports the argument that viewing the three categories of contractors holistically in construction research needs serious consideration. However, an economic case-related factor, 'high cost of H\&S self-regulation' ranks highest overall with a mean score (MS) of 3.70. The said factor then ranks $2^{\text {nd }}$ for large-sized contractors and medium sized contractors, but $1^{\text {st }}$ for small-sized contractors.

According to Table 1, the $2^{\text {nd }}$ overall ranking factor is 'lack of awareness' which is 'ability to self-regulate' related. However, it does not rank high for smallsized contractors but ranks ninth with an MS of 2.50, but ranks highest for medium sized contractors with an MS of 3.95. Lack of management commitment ranks $3^{\text {rd }}$ overall with the MS 3.25, while it also ranks $3^{\text {rd }}$ for medium-sized contractors with an MS of 3.32. The said factor then ranks $4^{\text {th }}$ for large-sized and small-sized contractors with MSs of 3.25 and 3.42 respectively. 
Table 1. The Perceptions of the Respondents on the Barriers to H\&S Self-regulation

\begin{tabular}{|c|c|c|c|c|c|c|c|c|}
\hline \multirow{2}{*}{$\begin{array}{c}\text { Conditions that do not support } \\
\text { H\&S self-regulation }\end{array}$} & \multicolumn{2}{|c|}{ Small sized } & \multicolumn{2}{|c|}{ Medium sized } & \multicolumn{2}{|c|}{ Large sized } & \multicolumn{2}{|c|}{ Overall } \\
\hline & Mean & Rank & Mean & Rank & Mean & Rank & Mean & Rank \\
\hline High cost of H\&S self-regulation & 3.75 & 1 & 3.84 & 2 & 3.46 & 2 & 3.70 & 1 \\
\hline Lack of H\&S awareness & 2.50 & 9 & 3.95 & 1 & 3.00 & 4 & 3.27 & 2 \\
\hline Lack of management commitment to H\&S & 3.42 & 4 & 3.32 & 3 & 3.00 & 4 & 3.25 & 3 \\
\hline Lack of resources & 3.17 & 5 & 3.00 & 7 & 3.54 & 1 & 3.20 & 4 \\
\hline $\begin{array}{l}\text { Lack of concern for the reputation of the } \\
\text { firm or industry }\end{array}$ & 3.42 & 4 & 3.21 & 5 & 2.92 & 5 & 3.19 & 5 \\
\hline $\begin{array}{l}\text { Negative attitudes in the construction } \\
\text { supply chain }\end{array}$ & 3.58 & 2 & 2.89 & 9 & 2.70 & 8 & 3.02 & 6 \\
\hline Low level of influenceability in the society & 3.50 & 3 & 3.26 & 4 & 2.15 & 14 & 3.00 & 7 \\
\hline $\begin{array}{l}\text { The assurance of no prosecution for non- } \\
\text { involvement in H\&S }\end{array}$ & 3.00 & 6 & 3.21 & 5 & 2.62 & 9 & 2.98 & 8 \\
\hline $\begin{array}{l}\text { Lack of a positive organizational culture } \\
\text { towards H\&S }\end{array}$ & 2.75 & 7 & 2.95 & 8 & 3.23 & 3 & 2.98 & 8 \\
\hline $\begin{array}{l}\text { H\&S is not a minimum requirement by our } \\
\text { clients }\end{array}$ & 3.17 & 5 & 2.84 & 10 & 2.77 & 7 & 2.91 & 9 \\
\hline $\begin{array}{l}\text { Organizational norms and values that do } \\
\text { not support H\&S }\end{array}$ & 2.25 & 11 & 2.89 & 9 & 2.78 & 7 & 2.68 & 10 \\
\hline $\begin{array}{l}\text { The perception that the regulatory activities } \\
\text { are unfair. }\end{array}$ & 2.33 & 10 & 2.79 & 11 & 2.46 & 11 & 2.57 & 11 \\
\hline Inadequate H\&S legislation & 2.75 & 7 & 2.16 & 17 & 3.00 & 3 & 2.57 & 11 \\
\hline $\begin{array}{l}\text { Inadequate external involvement in } \\
\text { regulatory activities }\end{array}$ & 1.75 & 16 & 2.95 & 8 & 2.77 & 7 & 2.57 & 11 \\
\hline Small scope of operation & 2.58 & 8 & 2.74 & 12 & 2.31 & 13 & 2.57 & 11 \\
\hline $\begin{array}{l}\text { Low level of organizational involvement in } \\
\text { H\&S regulation }\end{array}$ & 2.50 & 9 & 2.53 & 14 & 2.62 & 9 & 2.55 & 12 \\
\hline $\mathrm{H} \& \mathrm{~S}$ is not a duty & 1.75 & 16 & 2.84 & 10 & 2.54 & 10 & 2.45 & 13 \\
\hline Negative pressure from the industry & 1.83 & 15 & 2.74 & 12 & 2.54 & 10 & 2.43 & 14 \\
\hline $\begin{array}{l}\text { The perception that H\&S legislation or } \\
\text { standards is unfair }\end{array}$ & 2.00 & 14 & 3.05 & 6 & 1.85 & & 2.40 & 15 \\
\hline $\begin{array}{l}\text { Negative peer-pressure from other } \\
\text { companies }\end{array}$ & 2.08 & 13 & 2.16 & 17 & 2.77 & 7 & 2.32 & 16 \\
\hline H\&S is not the right thing & 1.67 & 17 & 2.68 & 13 & 2.31 & 13 & 2.30 & 17 \\
\hline Complex H\&S legislation, standards & 1.75 & 16 & 2.21 & 16 & 2.77 & 6 & 2.25 & 18 \\
\hline Negative pressure from pressure groups & 1.58 & 18 & 2.26 & 15 & 2.62 & 9 & 2.18 & 19 \\
\hline $\begin{array}{l}\text { Negative pressure from stakeholders in the } \\
\text { organization }\end{array}$ & 1.83 & 15 & 2.11 & 18 & 2.54 & 10 & 2.16 & 20 \\
\hline $\begin{array}{l}\text { Perception that self-regulation is not } \\
\text { important }\end{array}$ & 1.83 & 15 & 2.21 & 16 & 2.08 & 15 & 2.07 & 21 \\
\hline $\begin{array}{l}\text { Negative pressure from members of the } \\
\text { construction supply chain }\end{array}$ & 2.00 & 14 & 1.79 & 21 & 2.38 & 12 & 2.02 & 22 \\
\hline $\begin{array}{l}\text { Outcomes of lawsuits perceived to be unfair } \\
\text { or inadequate }\end{array}$ & 2.08 & 13 & 1.89 & 19 & 2.15 & 14 & 2.02 & 23 \\
\hline Negative attitude of client towards H\&S & 2.17 & 12 & 1.84 & 20 & 2.00 & 16 & 1.98 & 24 \\
\hline
\end{tabular}

Table 1 goes further to show that from an organizational case perspective, 'lack of resources', for example, person power ranks $4^{\text {th }}$ overall with the $\mathrm{MS}$ of 3.20. However, in terms of size of contractors, the respondents from large-sized contractors view it as the highest barrier to H\&S self-regulation with the MS of 3.54, but the respondents from medium-sized contractors do not view it as a strong barrier where it ranks $7^{\text {th }}$ with an MS of 3.00 and $5^{\text {th }}$ for small-sized contractors with the MS 3.17.

Other revealing findings in Table 1 include the 'Negative attitude in the construction supply chain' which is viewed by the respondents from small-sized contractors as a major barrier, as it has the MS of 3.58 hence ranks $2^{\text {nd }}$, but not viewed the same among the respondents from the other two categories of contractors. More specific questions relating to the members of the construction supply chain offer a further explanation. Firstly, using an industry case factor the negative attitude of the client towards H\&S has been assessed. This is where the respondents have been asked whether situations where clients do not want H\&S to be included in the contract will be a barrier to H\&S self-regulation. It was found that from the perspective of the respondents, it ranked $24^{\text {th }}$ with an overall MS of 1.98 . In terms of the sizes of the companies, the respondents 
from small-sized contractors view it as a higher barrier than others. Another question investigating the implications with respect to the members of the construction supply chain the 'negative attitude of the members of the construction supply chain e.g sub-contractors' ranks $22^{\text {nd }}$ overall with the MS of 2.02. It also ranks low as per size of the company.

Equally important is the power of relationship case factor, 'low level of influenceability in the society' where it ranks $3^{\text {rd }}$ for the small-sized contractors with the MS of 3.50 and $4^{\text {th }}$ for the respondents from the medium-sized contractors with an MS of 3.26. Conversely, Table 1 shows that the low level of influenceability in the society' ranks $14^{\text {th }}$ for largesized contractors with an MS of 2.15.

Statistically Significant Differences in the Responses of Large, Medium and Small-sized Contractors on the Barriers to Health and Safety Self-regulation

The one-way ANOVA test shows that there are statistically significant differences in the responses of the small, medium, and large-sized construction contractors on the six factors below. Then the Tukey HSD tests show the exact two groups where the differences are. The latter further shows an additional factor, with the difference between two groups. The significance level for the ANOVA and the Tukey test were set at $<0.05$.

For the one-way ANOVA, there is a statistical significant difference between groups for the factor, the 'perception that H\&S legislation or standards are unfair' $[\mathrm{F}(2,41)=6.729, \mathrm{p}=0.003]$. The Tukey test then shows that the difference is between the medium-sized contractors and the small-sized contractors $(p=0.021)$, and between the medium-sized contractors and large-sized contractors $(p=0.006)$. Conversely, there is no difference between smallsized contractors and large-sized contractors $(\mathrm{p}=$ 925)

The ANOVA test further reveals a statistical difference on the factor ' $\mathrm{H} \& S$ is not a duty $[\mathrm{F}(2,41)=$ 3.509, $\mathrm{p}=0.39]$ '. The Tukey HSD test then reveals that the difference is between the small-sized contractors and medium-sized contractors $(p=0.031)$. However, there is no difference between small-sized contractors and large-sized contractors $(p=0.200)$, and between medium-sized contractors and largesized contractors $(p=0.736)$

For the factor 'H\&S is not the right thing', the ANOVA test shows a difference among the three groups $[\mathrm{F}(2,41)=4.951, \mathrm{p}=0.012]$ ', then a probe of the result by Tukey test narrows the difference to exist between small-sized contractors and mediumsized contractors $(p=0.008)$, but no difference between small-sized contractors and large-sized contractors $(p=0.174)$ and between medium-sized contractors and large-sized contractors $(p=0.464)$.

Another factor with a significant difference among the three groups in the ANOVA test is the lack of H\&S awareness' $[\mathrm{F}(2,41)=3.512, \mathrm{p}=0.039]$. Again the Tukey test shows that the difference exists between the small-sized contractors and mediumsized contractors $(p=0.039)$, but no difference between the small-sized and large-sized contractors ( $p=$ $0.700)$ and between the medium-sized contractors and the large-sized contractors $(p=0.216)$

The ANOVA test showed a significant difference on the 'inadequate level of external involvement in regulatory activities' $[\mathrm{F}(2,41)=4.494, \mathrm{p}=0.017]$ '. The Tukey test then revealed that the differences are between the small-sized contractors and the medium-sized contractors $(p=0.016)$, but there is no difference between the small-sized contractors and the large-sized contractors $(p=0.071)$ and between the large-sized contractors and medium sized contractors $(p=0.898)$.

Most importantly, the power relationship case factor the 'level of influenceability in the society' is another place that the ANOVA test shows a significant difference $[\mathrm{F}(2,41)=5.773, \mathrm{p}=0.006]$. The Tukey then narrows it down to the small-sized contractors and large-sized contractors $(p=0.010)$ likewise between medium-sized contractors and large-sized contractors $(p=0.019)$. This leaves no difference between small-sized contractors and medium sized contractors $(p=0.826)$.

Lastly, while the ANOVA test does not show a difference in the groups on the factor 'negative pressure from pressure groups' $[\mathrm{F}(2,41)=3.082, \mathrm{p}=0.057]$, the Tukey test shows a difference between the smallsized contractors and the large-sized contractors $(\mathrm{p}=$ 0.049), but no difference between the medium-sized contractors and the small-sized contractors $(p=$ 0.200) and no difference between the large-sized contractors and the medium-sized contractors $(\mathrm{p}=$ 0.626).

\section{Discussion}

The findings of this study are consistent with the position of many authors, for example, Anderson and Russell [19], Agumba and Haupt [23], where small and medium-sized companies are highly hindered from H\&S because of financial reasons. It is, however, found that even large-sized contractors consider the high cost of H\&S as a very significant hindrance 
to H\&S, especially from a regulatory perspective (Table 1). There are a few possible explanations to this. For instance, regulating the subcontractors and some medium-sized contractors who may be forced to meet the requirements of large contractors may pose a financial burden to the large contractors. This finding is further strengthened by the results of the ANOVA and Tukey tests, as there is no significant difference in the aforesaid factor. It also tends to be adduced by the finding, 'lack of resources' such as person power which ranks highest for large-sized contractors with an MS of 3.54 (Table 1).

The finding that 'lack of H\&S awareness' ranks $2^{\text {nd }}$ overall with an MS of 3.37 , 9 $9^{\text {th }}$ for small-sized contractors with MS of $2.50,1^{\text {st }}$ for medium-sized contractors with MS of 3.95 and $4^{\text {th }}$ for large-sized contractors with MS of 3.00 is revealing (Table 1). This is because the lack of H\&S awareness is found in many studies (for example [24]), to hinder H\&S in small contractors where $80 \%$ of the respondents agree to safety awareness related questions. This is against large-sized contractors who based on their H\&S record in studies such as Windapo and Jegede [4] are expected to have a high level of H\&S awareness. Table 1 goes further to show that from an H\&S self-regulatory perspective, the three categories of contractors tend not to care about their image. Thus, in Nigeria, targeting the image of contractors may not be effective as it would be in developed countries.

In addition to Table 1, the result from the ANOVA and Tukey tests is consistent with the literature review, showing the impact of the size of companies on H\&S. The significant differences between the large and the small-sized, the large and the mediumsized, but not between the small and medium-sized contractors in term of the low level of influenceability in the society' is intriguing. It indicates that in terms of power relationship, large-sized contractors view their level of influenceability in the society as a driver to H\&S self-regulation more than the other two. This may be explained by the financial power of the large-sized contractors due to the high value of projects that they handle (cf. [17]). Handling such high-value projects may mean having close association or relationship with people in the higher echelon of power in the society. It is also possible that the people in the high echelon of the society may be executives or shareholders in these large contractors. Thus, working with the results of the Tukey test, in terms of this factor, the small and the medium-sized contractors can be viewed the same provided the issue relates only to both.

Of the seven factors where there are differences, there are differences between small-sized contractors and medium-sized contractors in four factors namely, 'H\&S is not a duty', 'H\&S is not the right thing', lack of H\&S awareness', and 'inadequate level of external involvement'. By implication, to get more contractors to self-regulate in terms of H\&S or to encourage those self-regulating H\&S wise, the factors in this paragraph should not be addressed as having the same impact on the small-sized contractors and medium-sized contractors.

\section{Conclusions}

Adopting a quantitative approach, the barriers to construction H\&S self-regulation in Nigeria have been identified, assessed, analyzed and presented in this paper. As a consequence, although a scoping study, it contributes to the understanding of the varied impact of the barriers of H\&S self-regulation considering the size of contractors. There is evidence in this study that in terms of H\&S self-regulation, the three categories of contractors, large, medium and small-sized, are highly limited by the high cost of H\&S self-regulation, as it ranks highest overall and $1^{\text {st }}$ and $2^{\text {nd }}$ among the contractors respectively. This contests the notion that only the small and medium-sized contractors experience financial difficulty. The impact of lack of H\&S awareness and the lack of management commitment are also highly ranked factors overall. The study also shows statistically significant differences between the group means of the responses of the large, medium and small-sized contractors, where out of the seven factors with the significant differences, the small and the medium-sized contractors are different in four factors. The factors are 'H\&S is not a duty', 'H\&S is not the right thing' (which are related to molarity), 'lack of H\&S awareness', (that fall under the ability to self-regulate) and 'inadequate level of external involvement' (which is under the regulatory case).

The findings of the current study imply that addressing the regulation of construction H\&S from a holistic perspective (as against in terms of the size of the contractors) needs a rethink. However, as the significant differences in the responses of the three categories of contractors are in only seven of the 28 barriers, it can be argued that a holistic approach to addressing construction H\&S regulation matters in Nigeria may still be effective but may not be pragmatic. The findings of the study also imply that economic factors, H\&S awareness-related factors, and management commitment factors may require more attention so as to encourage H\&S self-regulation; of course, this is from a holistic perspective.

The small sample of the study makes the generalization of the finding difficult; however, the findings can be viewed as indicative, besides, this is a scoping study. Consequently, a study with a larger sample is recommended. 


\section{References}

1. Idoro, G.I., Health and Safety Management Efforts As Correlates of Performance in the Nigerian Construction Industry, Journal of Civil Engineering and Management, 14(4), 2008, pp. 277-285.

2. Idoro, G.I., Comparing Occupational Health and Safety (OHS) Management Efforts and Performance of Nigerian Construction Contractors, Journal of Construction in Developing Countries, 16(2), 2011, pp.151-173.

3. Waziri, B.S., Hamma-adama, M., and Kadai, B., Exploring Health and Safety Practices on Some Nigeria Construction Site, Laryea, S. Leiringer, R. (Eds) Proceedings of the $6^{\text {th }}$ West Africa Built Environment Research (WABER) Conference, Accra, Ghana, 2015, pp. 491 - 502.

4. Windapo, A.O. and Jegede, O.P.A., Study of Health, Safety and Environment (HSE) Practices of Nigerian Construction Companies, The Professional Builder, 4(1), 2013, pp. 92-103.

5. Diugwu I.A., Baba D.L., and Egila A.E., Effective Regulation and Level of Awareness: An Expose of the Nigeria's Construction Industry, Open Journal of Safety Science and Technology, 2, 2012, pp. 140-146.

6. Umeokafor, N.I., Umeadi, B., and Jones, K.G., Compliance with Occupational Health and Safety Regulations: A Review of Nigeria's Construction Industry, Ejohwomu, O. \& Oshodi, O. (eds), Proceedings of the $3^{\text {rd }}$ International Conference on Infrastructure Development in Africa, ICIDA, Abeokuta, Nigeria, 2014, pp. 70-84.

7. Federal Republic of Nigeria, National Building Code, $1^{\text {st }}$ Ed. Capetown: LexisNexis Butterworths, 2006.

8. Omeife, C.A. and Windapo, O.A., The Impact of National Building Code on Professionalism, Proceedings of the 43rd Builders Conference AGM, Abuja, 2013, pp. 1-12.

9. Umeokafor, N.I. and Isaac, D., A Framework for Analyzing the Determinants of Health and Safety Self-Regulation in the Construction Industry, In Behm, M. and McAleenan (Ed.), Proceedings of the International Council for Research and Innovation in Building and Construction (CIB) W099 International Health and safety Conference, Jordanstown Campus, Northern Ireland, UK, 2015, pp. 478-487.

10. Aalders, M., and Wilthagen, T., Moving Beyond Command and Control: Reflectivity in the Regulation of Occupational Safety and Health and the Environment, Law and Policy, 19(4), 1997, pp. 415-443.

11. Christmann, P. and Taylor, G., Globalization and the Environment: Determinants of Firm
Self-regulation in China, Journal of International Business Studies, 32(3), 2001, pp. 439-458.

12. Havinga, T., Private Regulation of Food and Safety by Supermarkets, Law and Policy, 28(4), 2006, pp. 516-533.

13. Hutter, B., Is Enforced Self-regulation a Form of Risk Taking?: The Case of Railway Health and Safety, International Journal of the Sociology of Law, 29(4), 2001, pp. 379-400.

14. Finger, S.R. and Gamper-Rabindran, S., Testing the Effects of Self-regulation on Industrial Accidents, Journal of Regulatory Economics, 43(43), 2013, pp. 115-146.

15. Scharrer, A., Command vs. Self-regulation in Construction Safety: A Case Study of CHASE. (Master of Science thesis, The University of New Mexico), 2011. Retrieved from http://repository. unm.edu/bitstream/handle/1928/13108/A\%20Sc harrer\%20Thesis.pdf?sequence=1\&isAllowed=y, (accessed August 12-2015).

16. Kheni, N.A., Gibb, A.G.F., and Danity, A.J.F., The Management of Construction Sites Health and Safety by Small and Medium Sized Construction Businesses in Developing Countries: A Ghana Case Study, Boyd, D. (Ed), Proceedings of the 22 $2^{\text {An }}$ Annual ARCOM Conference, Birmingham, UK, 2006, pp. 273-282.

17. Mills, A. and Lin, J., Effect of Company Size on Occupational Health and Safety, The International Journal of Construction Management, 4(1), 2004, pp. 29-39.

18. Vickers, I., James, P., Smallbone, D., and Baldock, R., Understanding Small Firms Responses to Regulation: The Case of Workplace Health and Safety, Policy Studies, 26(2), 2005, pp. 149-169.

19. Anderson, A.R. and Russell, E.O., Self-regulation: A Strategic Alternative for Small Firms?, Journal of Business Strategy, 32(4), 2011, pp. 42-47.

20. Walls, C.B. and Dryson, E.W., Failure after 5 Years of Self-regulation: A Health and Safety Audit of New Zealand Engineering Companies Carrying Out Welding, Occupational Medicine, 52(6), 2002, pp. 305-309.

21. Wright, M.S., Factor Motivating Health and Safety Management, Health and Safety Executive (HSE) Contract Research Report 179/1998, HSE Books, 1998.

22. Aniekwu, N., Accidents and Safety Violations in the Nigerian Construction Industry, Journal of Science and Technology, 27, 2007, pp. 81-89.

23. Agumba, J. and Haupt, T., Evaluating Management Commitment to Health and Safety in Small and Medium Construction Enterprises, Proceedings of the $6^{\text {th }}$ Postgraduate Conference on Construction Industry Development, Johannesburg, 2009, pp. 323-333. 
24. Wong, J.Y., Gray, J., and Sadiqi, Z., Barriers to Good Occupational Health and Safety Practices by Small Construction Firms, Journal of Construction Management, 1, 2015, pp. 55-66.

25. Factories Act, CAP F1, LFN, Federal Government Press, Abuja, Nigeria, 2004.

26. Lagos State Safety Commission Law passed Bill, 2011. Retrieved from http://lagoshouseofassembly.gov.ng/bill (assessed December 9 2015).

27. Gunningham, N., Investigation of Industry Selfregulation in Workplace Health and Safety in New Zealand, Gunningham \& Associates Pty Ltd, 2011, Retrieved from http://www.dol. govt.nz/whss/resources/investigation-industryself-regulation-whss-nz.pdf (accessed November 20 2013).

28. Fairman, R. and Yapp, C., Enforced Self-regulation, Prescription, and Conceptions of Compliance within Small Business: The Impact of Enforcement, Law and Policy, 27(4), 2005, pp. 491-519.

29. King, A.A. and Lenox, M. J., Industry Self-regulation without Sanctions: The Chemical Industry's Responsible Care Program, Academic of Management Journal, 43(4), 2000, pp. 698-716.

30. Giuliano, G. and Linder, A., Motivations for Self-regulation: The Clean Air Action Plan, Energy Policy, 59, 2013, pp. 513-522.

31. Winter, S.C. and May, P.J., Motivation for Compliance with Environmental Regulations, Journal of Policy Analysis and Management, 20(4), 2001, pp. 675-698.
32. Lane, D.M, The Tukey HSD is not a Post Hoc Test, n.d. Retrieved from http://davidmlane.com/hyperstat/essays/tukey_test.html (assessed December 5 2015)

33. Welkowitz, J., Cohen, B.H., and Brooke, R. Introductory Statistics for the Behavioral Sciences, $7^{\text {th }}$ ed., John Wiley and Sons, New Jersey, 2012.

34. Puplampu, B.B. and Quartey, S.H., Key Issues on Occupational Health and Safety Practices in Ghana: A Review, International Journal of Business and Social Science, 3(19), 2012, pp. 151-156.

35. Tanko, B.L. and Anigbogu, N.A., The Use of Personal Protective Equipment (PPE) on Construction Sites in Nigeria, Laryea, S., Agyepong, SA., Leiringer, R., and Hughes, W., (Eds), Proceedings of the $4^{\text {th }}$ West Africa Built Environment Research (WABER) Conference, 24-26 July 2012, Abuja, Nigeria, 13411384.

36. Sauro, J., Best Practices for Using Statistics on Small Sample Size, 2013. Retrieved, from www.measuringu.com/blog/small-n.php, (accessed May 2, 2016)

37. Umeokafor, N.I., Approaches, Drivers and Motivators to Health and Safety Self-regulation in the Nigerian Construction Industry: A Scoping Study, Architectural Engineering and Design, 12(6), 2016, pp. 460-475.

38. Ramos, A.K., Axel Fuentes, A., and Trinidad, N., Perceptions of Job-related Risk, Training, and Use of Personal Protective Equipment (PPE) among Latino Immigrant Hog CAFO Workers in Missorui: A Pilot Study, Safety, 2(4), 2016, pp.1-10. 